\title{
Revisiting current treatment options for stress urinary incontinence and pelvic organ prolapse: a contemporary literature review
}

This article was published in the following Dove Press journal: Research and Reports in Urology

You (Maria) Wu'

Blayne Welk ${ }^{2}$

'Department of Obstetrics and Gynecology, London Health Sciences Centre, London, Ontario, Canada;

${ }^{2}$ Department of Surgery and

Epidemiology \& Biostatistics, Western University, London, Ontario, Canada
Correspondence: Blayne Welk

St Joseph's Health Care, Room B4-667,

268 Grosvenor Street, London, Ontario

N6A 4V2, Canada

Tel + I 5196466367

$\mathrm{Fax}+15196466037$

Email bkwelk@gmail.com

\begin{abstract}
Stress urinary incontinence (SUI) and pelvic organ prolapse (POP) affect many women in their lifetime. In this review, we describe and evaluate the latest treatment options for SUI and POP, including the controversy around transvaginal mesh (TVM) use. Growing evidence supports the utilization of pelvic floor muscle training as first-line treatment for both SUI and POP. Vaginal pessaries continue to be an effective and reversible option to manage SUI and POP symptoms. The midurethral sling remains the gold standard for surgical treatment of SUI, although patients and clinicians should acknowledge the potentially serious complications of TVM. Burch urethropexy and pubovaginal sling offer good SUI cure and may be preferred in women wishing to avoid mesh implants; however, their operative morbidities and more challenging surgical approach may limit their use. Sitespecific cystocele or rectocele repairs may be indicated for isolated anterior or posterior vaginal compartment prolapse; however, in women with more severe POP, evidence supports using a vaginal native-tissue repair involving apical suspension as the primary surgical technique. Although abdominal and laparoscopic sacrocolpopexies are both effective in treating POP, their failure and mesh complication rates increase with time. There is insufficient evidence to support the widespread use of uterine-preserving surgical POP repairs at present due to the lack of long-term data. Routine TVM use is not recommended in POP surgeries and should only be considered on a case-by-case basis by trained surgeons, primarily in women with multiple risk factors for POP recurrence. In general, clinicians should individualize SUI and POP treatment options for women based on their symptoms, comorbidities, and risk factors for mesh-related complications.
\end{abstract}

Keywords: stress urinary incontinence, pelvic organ prolapse, midurethral sling, transvaginal mesh, apical suspension, native tissue repair

\section{Introduction and review objectives}

Stress urinary incontinence (SUI), the involuntary leakage of urine on physical effort or exertion, and pelvic organ prolapse (POP), the descent of pelvic organs from their normal positions in the pelvis, are common conditions that affect $30-40 \%$ of the women in their lifetime. ${ }^{1,2}$ Although SUI and POP are non-lifethreatening illnesses, they confer a significant health care burden in the aging population and lead to negative impacts on women's quality of life. SUI arises from the decreased support of the pelvic floor and vaginal connective tissue around the bladder neck and urethra, 3 while POP is a result of weakness at various levels of the endopelvic fascia and levator ani muscle complex. ${ }^{4}$ Concurrent SUI often 
exists in women with POP due to the similar pathophysiology between these two conditions. Risk factors for SUI and POP include but are not limited to pregnancy and vaginal parity, forceps delivery, age, menopause, prior pelvic reconstructive surgeries, and chronic straining. ${ }^{5}$

In this review, we aim to describe the latest trends in SUI and POP treatment, with a focus on the literature surrounding the efficacy and complications from the past 5 years. Conservative management of SUI and POP most commonly consists of pelvic floor muscle training (PFMT) and vaginal pessaries, whereas surgical treatment of SUI and POP may involve either native-tissue or mesh-based repairs in the abdominal, laparoscopic, or vaginal approach. We also provide an appraisal and update on the ongoing controversies regarding transvaginal mesh (TVM) use in SUI and POP.

\section{Literature search and data synthesis}

We conducted a literature search limited to January 1, 2014 to February 25, 2019 for studies of PFMT, vaginal pessaries, and mesh- and native-based surgical repairs for SUI and POP. We included systematic reviews and meta-analyses, RCTs, large prospective cohort studies and retrospective cohort studies in our data synthesis. Case-control studies, case series, and case reports are not included unless they pertained to rarer treatments of SUI and POP, or where more rigorous study designs were not available. Updates to systematic reviews and secondary analyses of RCT data conducted prior to 2014 are included if the updates and data analyses on long-term follow-up were reported within the past 5 years.

\section{Conservative treatments for SUI and POP \\ PFMT}

There has been a growing body of evidence supporting PFMT for SUI and POP treatment in the past 5 years. PFMT is a structured and individualized program of exercises which aims to improve pelvic floor muscle strength, endurance, power, relaxation, or a combination of these parameters. ${ }^{6}$ PFMT may be performed with adjunctive therapies such as vaginal cones and electrical muscle stimulation, although limited evidence suggests there is no added benefit with these modalities. ${ }^{7,8}$ PFMT builds pelvic floor strength with repeated muscle contractions and enhances conscious muscle pre-contraction prior to anticipated increases in abdominal pressure such as coughing. ${ }^{9,10}$ Health care providers may tailor PFMT treatment programs to the degree of bothersome SUI and POP symptoms, the stage and severity of urinary leakage and prolapse, and basic fitness and comfort of each patient.

The most recent Cochrane review update consisting of 31 trials in 1,874 women supports PFMT as the first line therapy for SUI, with women in the PFMT group eight times more likely to report cure compared to inactive or no treatment. ${ }^{11}$ PFMT training protocols were individualized and progressive in all included trials, with higher patientreported cure and greater reduction of leakage episodes if protocols were supervised. The benefit of PFMT on SUI symptoms has also been demonstrated in the immediate postpartum period. A meta-analysis examining PFMT and postpartum UI by patient self-report symptoms and pad testing showed a $56 \%$ reduction in UI risk at 12 months postpartum in women receiving PFMT. ${ }^{12}$ Currently, the National Institute of Health and Care Excellence recommends a minimum of the 3-month trial of supervised PFMT as first-line treatment for SUI. ${ }^{13}$

PFMT is also effective in preventing and treating POP. A 2014 multicenter, parallel-group RCT of 447 women with stage 1-3 POP demonstrated a significant decrease in the POP symptom score (POP-SS) at 12 months, in women receiving one-to-one physiotherapist-led PFMT compared to those without training. ${ }^{14} \mathrm{~A}$ meta-analysis including 13 RCTs and 2,340 women across 10 countries also reported an improvement in both POP-SS and POP staging on POP-Q measurement in the PFMT group, 15 although overall evidence is limited by the heterogeneity of PFMT regimen and risk of performance bias. While current evidence of PFMT on postpartum POP remains limited, there appears to be an improvement in POP symptoms, but not anatomic stage, within 12 months postpartum in women undergoing regimented PFMT. ${ }^{12}$

Overall, current literature clearly demonstrates a benefit of routine and supervised PFMT on SUI and POP management. Further research on the long-term efficacy and cost effectiveness of PFMT is ongoing.

\section{Vaginal pessaries}

A pessary is an intra-vaginal device to support vaginal wall prolapse or to treat urinary incontinence. Pessaries may be used in women wishing to treat SUI and POP conservatively, or in women awaiting surgical correction of SUI and/or POP. Approximately $71-90 \%$ women can be successfully fitted with a pessary for either SUI or POP, with symptomatic relief in $70-90 \%$ of the women who undergo a successful pessary fitting. ${ }^{16}$ 
Vaginal devices for SUI treatment often provide additional support to the anterior vaginal wall to slightly elevate and constrict the urethra. ${ }^{17}$ These include the ring and dish pessaries with a knob, the anti-incontinence pessary ${ }^{18}$, and intra-vaginal inserts. Moderate quality evidence in a 2017 review suggests that vaginal pessaries significantly decrease urinary leakage and bother during physical activities in women with SUI. ${ }^{19}$ A single-blind, two-arm RCT in 2017 comparing women wearing the anti-incontinence pessary, vs a sham vaginal ring, showed a significant decrease in pad use in pessary users, ${ }^{20,23}$ although the trial is limited by the small number of participants and short duration of follow-up. Further research is needed to confer these findings and examine the long-term benefits of vaginal pessary use in the treatment of SUI.

Vaginal pessaries provide POP symptom improvement in $49-90 \%$ of the users. ${ }^{21,22}$ New studies on pessary use for POP treatment are scarce due to the established benefit of pessary use. A 2018 prospective cohort study in China on 142 women using ring with support pessaries for symptomatic POP showed a significant improvement in Pelvic Floor Distress index (PFDI-20) and Pelvic Floor Impact Questionnaire (PFIQ-7) scores, along with improved sexual function and overall quality of life. ${ }^{23}$ At 24 months, $74.8 \%$ patients continued to use the pessary. Known risk factors for pessary discontinuation include a wide vaginal introitus, ${ }^{23}$ increased parity, and previous hysterectomy, ${ }^{21}$ whereas factors predictive of long-term pessary use include older age, concurrent vaginal estrogen (VE) use, and smaller pessaries. ${ }^{24} \mathrm{VE}$ is often recommended in conjunction with pessary use for POP treatment in peri- or postmenopausal women to prevent pessary erosions and vaginitis. However, it is currently unclear whether VE in conjunction with pessary use improves treatment outcomes for women with POP.

\section{Surgical treatments for SUI}

Surgical management of SUI is often indicated when conservative therapies fail, or if patients are desirous of definitive management while accepting the risks of surgery. Surgery offers a high rate of cure in general, although the short- and long-term success rates for each method varies. We emphasize the three most common surgical methods to treat SUI in this review, including the midurethral sling (MUS), Burch retropubic urethropexy, and autologous pubovaginal sling (PVS). The ongoing controversy regarding TVM complications in SUI repair, along with current literature surrounding mesh use and surgeon expertise, is also discussed.

\section{Midurethral sling}

The MUS is a minimally invasive surgical technique for SUI treatment, with symptom cure rates of $75-94 \%$ and objective cure rates of $57-92 \% .{ }^{25}$ Compared to PFMT, women receiving a primary MUS for SUI report a higher subjective and objective cure at 1 year. $^{26,27}$ MUS most commonly involves the passage of a small strip of synthetic mesh through either the retropubic space (tension-free vaginal tape, TVT) or obturator foramen (trans-obturator tape, TOT or TVT-O, via the "inside-out" route). The TVT sites exit at the lower abdomen while TOT sites exit in the groin. Efficacy between the TVT and TOT is similar, as described in a 2009 Cochrane review of 12,113 women, with a slightly lower risk of major visceral and vascular injuries, blood loss and urinary retention in TOTs ${ }^{28}$ but a higher risk of groin pain. These findings are again confirmed in the most recent update of the review. ${ }^{25}$ Among all surgical approaches to treat SUI, the efficacy and safety profile of MUS have been the most extensively studied to date. TOT appears to be slightly more cost effective than TVT at 5 years post-op, although some evidence suggests a higher re-operation risk with TOT. ${ }^{29}$

Overall, MUS has excellent safety data, and provides satisfactory results for most women in the hands of experienced surgeons. ${ }^{30}$ A 2018 multicenter RCT comparing the TVT and Burch retropubic urethropexy showed a $19 \%$ higher rate of overall continence in the TVT arm at 2 years. ${ }^{31}$ The slight superiority of TVT against retropubic urethropexy and autologous fascia sling was also confirmed in a 2017 updated systematic review on all surgical methods to treat female SUI. ${ }^{32}$ A 2013 Nordic, multicenter cohort study of 90 women demonstrated an objective cure over $90 \%$ at 17 years post TVT placement, with only one case of asymptomatic mesh extrusion. ${ }^{33}$ Concurrent MUS placement may be performed at the time of POP surgeries to treat occult SUI, or as a stepwise treatment after POP repairs such as anterior colporrhaphy, when anterior colporrhaphy alone fails to achieve continence. MUS at the time of vaginal prolapse surgery results in a lower rate of de novo $\mathrm{SUI},{ }^{34}$ although the incidence of concurrent MUS procedures with POP surgery in the US has decreased by $16 \%$ since the 2011 FDA notification regarding TVM. ${ }^{35}$ While previous questions regarding polypropylene's carcinogenic properties were raised, a nationwide Swedish cohort study including over 5 million women clearly demonstrated no association with 
increased cancer risk in women undergoing polypropylene MUS surgeries. ${ }^{36}$

Complications of the MUS include bladder and urethral injury, voiding dysfunction, bleeding, infection, pelvic pain, dyspareunia, and mesh extrusion or exposure. In general, the complication rate for MUS appears to be lower than alternative non-mesh-based SUI surgeries. ${ }^{37}$ Mesh extrusion or erosion rate is low overall for MUS, occurring in an estimated $2.4 \%$ in women receiving TOTs and $2.1 \%$ in TVTs. ${ }^{25}$ The rate of re-operation and removal for MUS increases with time, with a UK population-based study demonstrating a $1.4 \%$ mesh removal rate at 1 -year post-MUS placement, and at 9 years, the rate becomes $3.3 \%{ }^{40}$ These findings support the conclusions that the MUS is generally efficacious and safe.

However, in recent years, regulatory warnings and media scrutiny on TVM have resulted in substantial doubts in the public regarding MUS safety. The United Kingdom has called for a public inquiry into the $\mathrm{TVM}^{38,39}$ and Australia, New Zealand, and Ireland decided to ban or halt TVM products in 2018. In 2019, the United States Federal Drug Agency order manufacturers to stop selling transvaginal prolapse mesh kits. The ongoing controversy around mesh complications has led to an increase in research on mental health outcomes related to MUS placement in recent years. Depression has been associated with symptom amplification and lower continence-related quality of life in women with SUI. A 2016 RCT compared SUI symptoms and sexual function between depressed and non-depressed women receiving a MUS. The authors found that depressed women had a worse baseline urinary and sexual function, but a greater improvement of SUI symptoms at 12 months. ${ }^{41}$ Depression also resolved in $83 \%$ of the women who received a MUS. However, surgical interventions post-MUS placement for mesh-related complications may adversely affect psychiatric outcomes. A Canadian population-based study utilizing multiplelinked administrative databases examining 57,611 women who underwent a MUS found a $21 \%$ higher hazard risk of depression in women who underwent a surgical correction for TVM complication, compared to women who did not; this risk was predominately found in younger women. ${ }^{42}$ These emerging data highlight the importance of evaluating psychiatric outcomes in women undergoing MUS, particularly the potential mental health consequences associated with MUS complications.

Further studies are required to demonstrate the long-term safety and efficacy of single-incision slings (mini-slings).
Specifically, the TVT-Secur was found to be inferior to traditional MUS in treating SUI, and was withdrawn from the market. ${ }^{43}$ Mini-slings are therefore not recommended for SUI treatment based on current evidence.

In general, MUSs are still considered the gold standard surgical treatment for female SUI. It is important to acknowledge that some patients do suffer serious complications which may not be easily corrected. However, most women experience subjective and objective improvement in SUI after treatment by an experienced surgeon. The use of MUSs is supported by numerous societies including the American Urology Association, Canadian Urology Association, Society for Urodynamics, Female Pelvic Medicine and Urogenital Reconstruction, International Urogynecological Association, and Society of Obstetricians and Gynecologists Canada.

\section{Burch urethropexy}

The Burch retropubic urethropexy, consisting of bilateral urethrovaginal fixation to Cooper's ligament via the abdominal approach, was first described in 1961. The Burch procedure was long regarded as the gold standard for SUI treatment prior to the emergence of MUS. Women undergoing the Burch urethropexy report an overall continence rate at $85-90 \%$ at 1 year and $70 \%$ at 5 years. ${ }^{44}$ The Burch procedure has been shown to be superior to the MarshallMarchetti-Krantz procedure and bladder needle suspensions in both continence rate and adverse events. ${ }^{44,45}$

Few new studies on Burch urethropexy have emerged in the past 5 years, although several meta-analyses and evidence summary of previous trials are available. The 2017 Cochrane review consisting of 55 trials in 5,417 women on open retropubic Burch urethropexy demonstrated its continued efficacy in treating SUI, especially in the long term. Specifically, the Burch urethropexy is equally effective as traditional PVSs within 1 year of treatment, although the efficacy appears to decrease with time. ${ }^{44}$ As an alternative to open surgery, the procedure can also be performed laparoscopically by trained surgeons. At 24 months post-op, laparoscopic Burch urethropexy is shown to be equally effective as an open Burch procedure in a 2018 Cochrane review of 22 RCTs, with two paravaginal sutures providing better objective cure than one suture. ${ }^{46}$ However, women undergoing laparoscopic Burch suspensions had a significantly longer operating time and hospital stay. Although Burch urethropexy is traditionally performed with open sacrocolpopexies (SCP) to treat SUI, recent evidence suggests that it may 
be inferior to the MUS in continence rates at both 1 and 2-year post sacrocolpopexy (SCP). ${ }^{31,47}$ This is possibly due to a lack of surgeon expertise in Burch urethropexy performance worldwide, compared to surgeon comfort in performing the MUS. ${ }^{48}$

\section{Pubovaginal Sling (PVS)}

Traditional autologous PVSs consist of harvesting autologous fascia from the anterior abdominal wall (rectus fascia sling) or the thigh (tensor fascia lata sling). Due to their longer operative time, higher blood loss and postoperative morbidities including seroma formation and long-term voiding dysfunction, PVSs are often reserved for women with recurrent SUI, severe SUI, a fixed urethra on examination, or previous complications with the MUS. ${ }^{49,50}$ PVSs may also be preferable in the setting of the urethral fistula or diverticulum repair due to their slightly more obstructive nature and concomitant urethral reinforcement with autologous fascia.

With the recent concerns around the synthetic TVM, traditional PVSs have re-emerged as a viable alternative to MUS in light of the potentially serious risks associated with TVM. ${ }^{51}$ The main advantage of PVSs is the lack of erosion risk due to inflammation and foreign body action associated with synthetic mesh material. However, the readoption of PVSs has been limited by the technical difficulty and surgeon expertise, and potential higher operative morbidities.

Currently, the quality of evidence on the PVS appears more variable due to heterogeneous populations, shorter duration of follow-up, and smaller sample sizes. ${ }^{52}$ A multicenter RCT in the UK demonstrated a success rate of $49-90 \%$ for autologous fascia slings at 10 -year follow-up. ${ }^{53}$ The latest updated systematic review and meta-analysis comparing PVSs with colpourethrosuspensions and MUS demonstrated similar success rates and postoperative voiding symptoms between PVS and MUS, with a trend towardlower re-operation in patients with MUS. ${ }^{32}$ The recent Cochrane review outlined the limitations of determining PVS-specific outcomes, which are smaller sample sizes, single center experiences, data inconsistency, and wide confidence intervals with each outcome. $^{52}$ PVSs appear to have comparable efficacy with Burch urethropexies, but long-term comparison between these two SUI repairs is lacking at present. ${ }^{52}$

In summary, the PVS appears to be an effective SUI treatment, which may be appealing to women who wish to avoid mesh implantation. However, the higher associated surgical morbidity, prolonged hospital stay, and restricted surgeon expertise may serve as barriers to the widespread use of PVSs in treating SUI. Larger and higher quality studies are needed to further elucidate the long-term outcomes associated with PVSs.

\section{Other surgical treatments of SUI}

Urethral bulking is often reserved for women who are unable to tolerate or wish to defer surgical management of SUI. A 2017 meta-analysis of 14 trials in 2004 women receiving various types of bulking agents including silicone particles, ethylene vinyl alcohol, carbon spheres, and autologous fat demonstrated no superiority of any bulking agent against placebo saline injection, although silicone particles combined with PFMT may be beneficial at 3 months. ${ }^{54}$ One included trial demonstrated a non-significant improvement in patient satisfaction after periurethral injection. Currently, an RCT comparing the efficacy of urethral bulking vs TVT on UI treatment in post-vulvectomy patients is in progress. ${ }^{55}$

Artificial urethral sphincter (AUS) may be indicated in women with refractory incontinence and severe intrinsic sphincter deficiency (ISD), ${ }^{56}$ and a 2018 case series of 74 women demonstrated the feasibility of laparoscopic AUS placement. ${ }^{57}$ However, due to the high risk of vaginal erosion and urinary tract infection associated with AUS placement in women, the AUS is not recommended as a first-line surgical treatment for SUI in female patients. On the other hand, bladder neck incision (BNI) has demonstrated success in cases of SUI secondary to primary bladder neck obstruction in women, although a small number of women report recurrent SUI and vesicovaginal fistula formation post BNI. ${ }^{58}$

Data remain insufficient to recommend the routine use of vaginal laser for SUI treatment at present.

\section{Surgical treatments for POP}

Women with symptomatic POP often benefit from surgical treatment in the setting of severe prolapse, failure of conservative therapy, or when definitive management is desired. It is estimated that by age $80,30 \%$ of the women with POP will have undergone at least one reconstructive surgery. ${ }^{59}$ The choice of a primary POP repair is affected by many patients and surgical factors, including age, POP stage, medical comorbidities such as obesity, and desire for future sexual activity. ${ }^{1}$ The most common surgical approaches for POP treatment will be reviewed here, including both native-tissue and mesh-based repairs. An evaluation of treatment efficacy, trends, controversies, and 
opportunities for further research for each repair method is also outlined.

\section{Native tissue POP repairs}

In the setting of severe or recurrent POP, isolated repair of the anterior or posterior vaginal compartment alone appears to have a high failure rate. In women with multiple medical comorbidities who do not desire future sexual activity, an obliterative procedure such as the Lefort colpocleisis offers a high cure rate, improved body image, and low rates of regret. ${ }^{60}$ However, for women wishing to remain sexually active, a reconstructive procedure is recommended. A site-specific repair such as vaginal cystocele (anterior) or rectocele (posterior) repair is minimally invasive and offers a short recovery time in women with isolated anterior or posterior compartment POP. Kelly bladder neck plications for treatment of latent or concurrent SUI are not effective at the time of anterior repair, and are therefore no longer recommended. ${ }^{61}$

The vaginal apex plays a crucial role in maintaining pelvic floor integrity. Vaginal apical suspension may, therefore, be the most important step in preventing and treating vaginal vault prolapse, and to prevent recurrent POP. As such, the number of native tissue vaginal apical suspensions for POP treatment has steadily increased over the past 20 years. $^{62}$ Over $85 \%$ of the women who received a primary POP repair involving the vaginal apex underwent a vaginal native tissue repair between 2003 and 2014, as captured by multiple-linked health administrative databases in Ontario, Canada. ${ }^{63}$

Methods of native-tissue vaginal apical POP repairs include the sacrospinous ligament suspension (SSLS), uterosacral ligament plication (USLP), iliococcygeus vaginal vault suspension and McCall culdoplasty. These procedures most commonly involve a hysterectomy, although the correction of uterine prolapse through cardinal ligament suspension, also referred to as the Manchester-Fothergill operation, offers excellent anatomical and subjective cure as described in recent cohort studies. ${ }^{64,65}$ A 2017 meta-analysis comparing sacrospinous hysteropexies involving uterine suspension with sutures, vs vaginal vault suspension at the time of vaginal hysterectomy, showed no difference in re-operation between the two approaches at 12-60 months. ${ }^{66}$

Prolapse awareness and recurrent prolapse may be more common in vaginal native-tissue repairs compared to mesh-based SCP, and the risk of repeat POP was 2.28 times higher in vaginal native tissue repairs based on a 2016 Cochrane review. ${ }^{67}$ However, these findings are increasingly challenged by more recent larger and rigorously conducted population-based cohort studies. A 2018 Canadian population-based study of 49,339 women undergoing primary apical POP repairs demonstrated no difference in re-operation risk between vaginal native tissue apical repairs and SCP, at an average of 7.14 years of follow-up. ${ }^{63}$ Two other large cohort studies utilizing the Scottish $^{68}$ and American ${ }^{69}$ hospital discharge datasets also showed no difference of re-operation rates or adverse events between native-tissue and mesh-based apical repairs of any method. At present, evidence favors offering women a native-tissue POP repair via the vaginal approach involving apical suspension as the first line surgical treatment in women with symptomatic POP. ${ }^{68}$

There does not appear to be a difference in efficacy between various methods of native-tissue apical repairs, although the evidence quality is limited by study imprecision, inconsistency, and inadequate methodological reporting. ${ }^{67}$ Results at the 5-year follow-up of the OPTIMAL RCT published in 2018 comparing rates of surgical failure and POP-SSs between the SSLS and USLP demonstrated an improvement in POP symptoms in both groups, with no difference between the SSLS and USLP. Surgical failure is high for both procedures at 5 years, at $61.5 \%$ for USLP and $70.3 \%$ for SSLS. ${ }^{70}$ Patients' quality of life sexual function and body image significantly improved post-op for both SSLS and USLP, with no significant difference between the two approaches. ${ }^{71}$ The rate of dyspareunia is around $10 \%$ at 2 years postoperatively for patients undergoing native tissue vaginal apical suspensions. Overall, native tissue vaginal apical suspensions are effective procedures to treat POP, but failure rates do increase with time. However, the rate of re-operation and quality of life does not seem to differ between various methods of vaginal apical repair, or when compared with SCP.

\section{Mesh-based POP repairs}

For isolated anterior or posterior compartment POP, the incidence of TVM or graft placement has decreased since the 2011 FDA warning. Compared to native tissue sitespecific repairs, there is no benefit in augmenting cystocele or rectocele repairs with mesh or biologic graft for improvement in POP symptoms, quality of life or reduction of adverse events, based on results from two parallel pragmatic multi-center RCTs published in $2016 .^{72}$ Twelve percent of women allocated to receive TVM experienced mesh extrusion within 2 years of initial 
operation. The odds of re-operation in women receiving trocar-guided or self-tailored TVM vaginal mesh for POP is 2.4 times higher than those receiving native-tissue sitespecific POP repairs, as reported in a 2017 Canadian guideline on TVM use. ${ }^{73}$ In addition, patients who require surgical treatment for TVM related complications, at least $20 \%$ of the women require one or more additional operations. $^{74,75}$ Due to the potential risk of significant adverse events related to TVM POP repairs, the Society of Obstetricians and Gynecologists Canada has recommended TVM POP repairs be limited to tertiary centers with high volumes, and specifically considered for women with levator avulsion, severe, or recurrent prolapse, or risk factors for chronic abdominal straining such as chronic constipation. $^{73}$

The SCP has long been regarded as the gold standard for treatment of POP. First described in 1957, the SCP corrects apical prolapse by anchoring the vaginal wall via polypropylene mesh to the anterior longitudinal sacral ligament at the S24 level, thus re-establishing a horizontal vaginal axis. ${ }^{76}$ SCP can be performed via an open abdominal approach (ASCP), laparoscopically (LSCP) or robotically (RSCP). Success rate of ASCP at 3 years is $78-100 \%$, with an overall mesh extrusion rate of 3.4\% ${ }^{76}$ LSCP and RSCP confer a similar short-term cure rate as the ASCP, and their efficacy against vaginal native tissue vault repairs is currently under investigation. ${ }^{77}$ Secondary analysis of the Prosthetic Pelvic Floor Repair trial in 2018 shows that laparoscopic SCP is also an effective option for primary anterior compartment prolapse repair, and offers a better preservation of sexual function and lower risk of mesh complication compared to $\mathrm{TVM}^{78}$

Although SCP mesh is placed abdominally and represents a different route of placement from TVM, the recent scrutiny and media attention on TVM have negatively impacted women's perception about SCP mesh. Only $2.7 \%$ of the women in Ontario, Canada received abdominal mesh-based POP repairs between 2003 and 2014. Although moderate quality evidence supports improved anatomical outcomes at 6-60 months of follow-up in ASCP compared to vaginal native tissue repairs, there appears to be no difference in re-operation over time between these two approaches. ${ }^{79}$ Patient-centered outcomes including dyspareunia, quality of life and body image did not differ between ASCP and vaginal native tissue repairs, while the rate of mesh extrusion was significantly higher in ASCP. By 7-year post-op, failure rate of the ASCP is estimated at $22-48 \%$, and there is a $10.5 \%$ risk of mesh erosion. ${ }^{80}$
Uterine-preserving mesh-based POP surgeries have gained attention over the past few years due to the lower theoretical risk of mesh exposure, blood loss, and surgical cost. A 2019 meta-analysis of 94 studies comparing all routes of hysteropexy against hysterectomy, including the use of TVM, shows a decrease in mesh exposure, operative time, blood loss, and surgical cost without a difference in POP recurrence. ${ }^{81}$ Specifically, the odds of urinary retention are $95 \%$ lower in women undergoing laparoscopic hysteropexy compared to vaginal or open hysteropexy approaches. The included studies are, however, mostly observational and 42 out of the 99 studies are of single-arm cohort studies or case series, thus limiting the overall evidence quality by study heterogeneity and imprecision. Long-term data for hysteropexy outcomes remain scarce, and few studies exist to compare different methods of hysteropexy against each other at present.

\section{Concluding remarks}

SUI and POP are prevalent, multifactorial conditions that confer a significant health care burden for women, especially in the aging population. Treatment for SUI and POP has evolved over the past five years with increasing evidence supporting routine, supervised PFMT as the firstline therapy in symptomatic women. Despite a paucity of new literature, vaginal pessaries continue to be a costeffective and acceptable treatment for SUI and POP, serving as a reasonable alternative to surgical management. With the ongoing controversy around mesh use in SUI and POP surgery, a trend toward non-mesh-based SUI repairs including the Burch urethropexy and PVS has emerged over the past few years. Although the MUS has low complication rates and remains the most extensively studied SUI treatment, health care providers should counsel women regarding the potential rare but serious meshrelated complications.

For the surgical treatment of symptomatic POP, the evidence increasingly favors native-tissue vaginal repairs involving apical suspension as the primary surgical approach in women with moderate to severe POP, and the routine use of TVM is no longer recommended. The recent FDA decision to discontinue TVM kits for prolapse will likely further limit this as a treatment option. Uterine preserving mesh-based POP repairs appear to have similar success rates and lower risks of complication, including mesh erosions, in the short term, but long-term data on hysteropexies are still lacking. 
Based on the available current evidence, we suggest that clinicians individualize SUI and POP treatments based on women's symptomology, medical comorbidities, and intra-operative risk factors.

\section{Disclosure}

The authors report no conflicts of interest in this work.

\section{References}

1. Jelovsek JE, Maher C, Barber MD. Pelvic organ prolapse. Lancet. 2007;369(9566):1027-1038. doi:10.1016/S0140-6736(07)60462-0

2. Komesu YM, Schrader RM, Ketai LH, Rogers RG, Dunivan GC. Epidemiology of mixed, stress, and urgency urinary incontinence in middle-aged/older women: the importance of incontinence history. Int Urogynecol J. 2016;27(5):763-772. doi:10.1007/s00192-015-2888-1

3. Padmanabhan P, Dmochowski R. Urinary incontinence in women: a comprehensive review of the pathophysiology, diagnosis and treatment. Minerva Ginecol. 2014;66(5):469-478.

4. Barber MD. Contemporary views on female pelvic anatomy. Cleve Clin J Med. 2005;72(Suppl 4):S3-11.

5. Weber AM, Richter HE. Pelvic organ prolapse. Obstet Gynecol. 2005;106(3):615-634. doi:10.1097/01.AOG.0000175832.13266.bb

6. Bo K, Frawley HC, Haylen BT, et al. An International Urogynecological Association (IUGA)/International Continence Society (ICS) joint report on the terminology for the conservative and nonpharmacological management of female pelvic floor dysfunction. Neurourol Urodyn. 2017;36 (2):221-244. doi:10.1002/nau.23107

7. Bertotto A, Schvartzman R, Uchoa S, Wender MCO. Effect of electromyographic biofeedback as an add-on to pelvic floor muscle exercises on neuromuscular outcomes and quality of life in postmenopausal women with stress urinary incontinence: a randomized controlled trial. Neurourol Urodyn. 2017;36(8):2142-2147. doi:10.1002/ nau. 23258

8. Dean NM, Ellis G, Wilson PD, Herbison GP. Laparoscopic colposuspension for urinary incontinence in women. Cochrane Database Syst Rev. 2006;(3):CD002239.

9. Dumoulin C, Hay-Smith J, Frawley H, et al. 2014 consensus statement on improving pelvic floor muscle training adherence: international continence society 2011 state-of-the-science seminar. Neurourol Urodyn. 2015;34(7):600-605. doi:10.1002/nau.22796

10. Dumoulin C, Glazener C, Jenkinson D. Determining the optimal pelvic floor muscle training regimen for women with stress urinary incontinence. Neurourol Urodyn. 2011;30(5):746-753. doi:10.1002/ nau. 21104

11. Dumoulin C, Cacciari LP, Hay-Smith EJC. Pelvic floor muscle training versus no treatment, or inactive control treatments, for urinary incontinence in women. Cochrane Database Syst Rev. 2018;10: Cd005654.

12. Wu YM, McInnes N, Leong Y. Pelvic floor muscle training versus watchful waiting and pelvic floor disorders in postpartum women: a systematic review and meta-analysis. Female Pelvic Med Reconstr Surg. 2018;24(2):142-149. doi:10.1097/SPV.0000000000000513

13. National Collaborating Centre for Ws, Children's H. National Institute for Health and Care Excellence: Clinical Guidelines. Urinary Incontinence in Women: The Management of Urinary Incontinence in Women. London: Royal College of Obstetricians and Gynaecologists (UK) Copyright (c) 2013 National Collaborating Centre for Women's and Children's Health; 2013.

14. Hagen S, Glazener C, McClurg D, et al. A multicentre randomised controlled trial of a pelvic floor muscle training intervention for the prevention of pelvic organ prolapse (PREVPROL). Neurourol Urodyn. 2014;33(6):852-853.
15. Li C, Gong Y, Wang B. The efficacy of pelvic floor muscle training for pelvic organ prolapse: a systematic review and meta-analysis. Int Urogynecol J. 2016;27(7):981-992. doi:10.1007/s00192-015-2846-y

16. Robert M, Schulz JA, Harvey M-A, et al. Technical Update on Pessary Use. J Obstetrics Gynaecol Canada. 2013;35(7):664-674. doi:10.1016/S1701-2163(15)30888-4

17. Komesu YM, Rogers RG, Rode MA, et al. Pelvic floor symptom changes in pessary users. Am J Obstet Gynecol. 2007;197(6):620.e1-. e6206. doi:10.1016/j.ajog.2007.08.013

18. Farrell SA, Baydock S, Amir B, Fanning C. Effectiveness of a new self-positioning pessary for the management of urinary incontinence in women. Am $J$ Obstet Gynecol. 2007;196(5):474.e1-e8. doi:10.1016/j.ajog.2006.11.038

19. Lukacz ES, Santiago-Lastra Y, Albo ME, Brubaker L. Urinary incontinence in women: a review. Jama. 2017;318(16):1592-1604. doi:10.1001/jama.2017.12137

20. Lovatsis D, Best C, Diamond P. Short-term Uresta efficacy (SURE) study: a randomized controlled trial of the Uresta continence device. Int Urogynecol J. 2017;28(1):147-150. doi:10.1007/s00192-016-3090-9

21. Fernando RJ, Thakar R, Sultan AH, Shah SM, Jones PW. Effect of vaginal pessaries on symptoms associated with pelvic organ prolapse. Obstet Gynecol. 2006;108(1):93-99. doi:10.1097/01. AOG.0000222903.38684.cc

22. Clemons JL, Aguilar VC, Tillinghast TA, Jackson ND, Myers DL. Patient satisfaction and changes in prolapse and urinary symptoms in women who were fitted successfully with a pessary for pelvic organ prolapse. Am J Obstet Gynecol. 2004;190(4):1025-1029. doi:10.1016/j.ajog.2003.10.711

23. Mao M, Ai F, Zhang Y, et al. Changes in the symptoms and quality of life of women with symptomatic pelvic organ prolapse fitted with a ring with support pessary. Maturitas. 2018;117:51-56. doi:10.1016/ j.maturitas.2018.09.003

24. Wolff B, Williams K, Winkler A, Lind L, Shalom D. Pessary types and discontinuation rates in patients with advanced pelvic organ prolapse. Int Urogynecol J. 2017;28(7):993-997. doi:10.1007/ s00192-016-3228-9

25. Ford AA, Rogerson L, Cody JD, Aluko P, Ogah JA. Mid-urethral sling operations for stress urinary incontinence in women. Cochrane Database Syst Rev. 2017;7:Cd006375. doi:10.1002/14651858. CD003881.pub4

26. Labrie J, Berghmans BL, Fischer K, et al. Surgery versus physiotherapy for stress urinary incontinence. $N$ Engl J Med. 2013;369 (12):1124-1133. doi:10.1056/NEJMoa1210627

27. Latthe PM, Singh P, Foon R, Toozs-Hobson P. Two routes of transobturator tape procedures in stress urinary incontinence: a meta-analysis with direct and indirect comparison of randomized trials. BJU Int. 2010;106(1):68-76. doi:10.1111/j.1464410X.2009.09051.x

28. Ogah J, Cody JD, Rogerson L. Minimally invasive synthetic suburethral sling operations for stress urinary incontinence in women. Cochrane Database Syst Rev. 2009;(4):CD006375.

29. Lier D, Robert M, Tang S, Ross S. Surgical treatment of stress urinary incontinence-trans-obturator tape compared with tension-free vaginal tape-5-year follow up: an economic evaluation. Bjog. 2017;124(9):1431-1439. doi:10.1111/14710528.14227

30. Welk B, Al-Hothi H, Winick-Ng J. Removal or revision of vaginal mesh used for the treatment of stress urinary incontinencevaginal mesh for the treatment of stress urinary incontinencevaginal mesh for the treatment of stress urinary incontinence. JAMA Surg. 2015;150(12):1167-1175. doi:10.1001/jamasurg .2015 .2590

31. Trabuco EC, Linder BJ, Klingele CJ, et al. Two-year results of burch compared with midurethral sling with sacrocolpopexy: a randomized controlled trial. Obstet Gynecol. 2018;131(1):31-38. doi:10.1097/ AOG.0000000000002415 
32. Fusco F, Abdel-Fattah M, Chapple CR, et al. Updated systematic review and meta-analysis of the comparative data on colposuspensions, pubovaginal slings, and midurethral tapes in the surgical treatment of female stress urinary incontinence. Eur Urol. 2017;72 (4):567-591. doi:10.1016/j.eururo.2017.04.026

33. Nilsson CG, Palva K, Aarnio R, Morcos E, Falconer C. Seventeen years' follow-up of the tension-free vaginal tape procedure for female stress urinary incontinence. Int Urogynecol J. 2013;24(8):1265-1269. doi:10.1007/s00192-013-2090-2

34. Wei JT, Nygaard I, Richter HE, et al. A midurethral sling to reduce incontinence after vaginal prolapse repair. $N$ Eng $J$ Med. 2012;366 (25):2358-2367. doi:10.1056/NEJMoa1111967

35. Drain A, Khan A, Ohmann EL, et al. Use of concomitant stress incontinence surgery at time of pelvic organ prolapse surgery since release of the 2011 notification on serious complications associated with transvaginal mesh. $J$ Urol. 2017;197(4):1092-1098. doi:10.1016/j.juro.2016.11.087

36. Altman D, Rogers RG, Yin L, Tamussino K, Ye W, Iglesia CB. Cancer risk after midurethral sling surgery using polypropylene mesh. Obstet Gynecol. 2018;131(3):469-474. doi:10.1097/ AOG.0000000000002496

37. Holdo B, Verelst M, Svenningsen R, Milsom I, Skjeldestad FE. Long-term clinical outcomes with the retropubic tension-free vaginal tape (TVT) procedure compared to Burch colposuspension for correcting stress urinary incontinence (SUI). Int Urogynecol J. 2017;28 (11):1739-1746. doi:10.1007/s00192-017-3345-0

38. Heneghan C, Aronson JK, Goldacre B, Mahtani KR, Pluddemann A, Onakpoya I. Transvaginal mesh failure: lessons for regulation of implantable devices. Bmj. 2017;359:j5515. doi:10.1136/bmj.j5515

39. Scottish Independent Review of the use, safety and efficacy of transvaginal mesh implants in the treatment of stress urinary incontinence and pelvic organ prolapse in Women. Available from: http:// www.gov.scot/Resource/0051/00515856.pdf. Accessed January 5 2019

40. Gurol-Urganci I, Geary RS, Mamza JB, et al. Long-term rate of mesh sling removal following midurethral mesh sling insertion among women with stress urinary incontinence. Jama. 2018;320 (16):1659-1669. doi:10.1001/jama.2018.14997

41. Siff LN, Jelovsek JE, Barber MD. The effect of major depression on quality of life after surgery for stress urinary incontinence: a secondary analysis of the trial of midurethral slings. Am J Obstet Gynecol. 2016;215(4):455.e1-e9. doi:10.1016/j.ajog.2016.04.039

42. Welk B, Reid J, Kelly E, Wu YM. Association of transvaginal mesh complications with the risk of new-onset depression or self-harm in women with a midurethral sling. JAMA Surg. 2019;154:358. doi:10.1001/jamasurg.2018.4644

43. Nambiar A, Cody JD, Jeffery ST, Aluko P. Single-incision sling operations for urinary incontinence in women. Cochrane Database Syst Rev. 2017;7:Cd008709. doi:10.1002/14651858.CD003881.pub4

44. Lapitan MCM, Cody JD, Mashayekhi A. Open retropubic colposuspension for urinary incontinence in women. Cochrane Database Syst Rev. 2017;7:Cd002912. doi:10.1002/14651858.CD003881.pub4

45. Glazener CM, Cooper K, Mashayekhi A. Bladder neck needle suspension for urinary incontinence in women. Cochrane Database Syst Rev. 2017;7:Cd003636. doi:10.1002/14651858.CD003881.pub4

46. Dean N, Ellis G, Herbison GP, Wilson D, Mashayekhi A. Laparoscopic colposuspension for urinary incontinence in women. Cochrane Database Syst Rev. 2017;7:Cd002239. doi:10.1002/ 14651858.CD003881.pub4

47. Trabuco EC, Klingele CJ, Blandon RE, et al. Burch retropubic urethropexy compared with midurethral sling with concurrent sacrocolpopexy: a randomized controlled trial. Obstet Gynecol. 2016;128 (4):828-835. doi:10.1097/AOG.0000000000001651

48. Wu MP, Long CY, Liang CC, Weng SF, Tong YC. Trends in reoperation for female stress urinary incontinence: a nationwide study. Neurourol Urodyn. 2015;34(7):693-698. doi:10.1002/nau.22648
49. Parker WP, Gomelsky A, Padmanabhan P. Autologous fascia pubovaginal slings after prior synthetic anti-incontinence procedures for recurrent incontinence: a multi-institutional prospective comparative analysis to de novo autologous slings assessing objective and subjective cure. Neurourol Urodyn. 2016;35(5):604-608. doi:10.1002/nau.22759

50. Milose JC, Sharp KM, He C, Stoffel J, Clemens JQ, Cameron AP. Success of autologous pubovaginal sling after failed synthetic mid urethral sling. $J$ Urol. 2015;193(3):916-920. doi:10.1016/j. juro.2014.09.038

51. Bang SL, Belal M. Autologous pubovaginal slings: back to the future or a lost art? Res Rep Urol. 2016;8:11-20. doi:10.2147/ RRU.S96957

52. Rehman H, Bezerra CA, Bruschini H, Cody JD, Aluko P. Traditional suburethral sling operations for urinary incontinence in women. Cochrane Database Syst Rev. 2017;7:Cd001754. doi:10.1002/ 14651858.CD003881.pub4

53. Khan ZA, Nambiar A, Morley R, Chapple CR, Emery SJ, Lucas MG. Long-term follow-up of a multicentre randomised controlled trial comparing tension-free vaginal tape, xenograft and autologous fascial slings for the treatment of stress urinary incontinence in women. $B J U$ Int. 2015;115(6):968-977. doi:10.1111/bju.12851

54. Kirchin V, Page T, Keegan PE, et al. Urethral injection therapy for urinary incontinence in women. Cochrane Database Syst Rev. 2017;7:Cd003881. doi:10.1002/14651858.CD003881.pub4

55. Palomba S Tension-free Vaginal Tape (TVT) versus bulking agent for the treatment of post vulvectomy urinary incontinence; 2013. Available from: https://clinicaltrials.gov/ct2/show/NCT01148290. Accessed May 15, 2019

56. Costa P, Poinas G, Ben Naoum K, et al. Long-term results of artificial urinary sphincter for women with type III stress urinary incontinence. Eur Urol. 2013;63(4):753-758. doi:10.1016/j.eururo.2012.03.008

57. Bracchitta D, Costa P, Borojeni S, Menard J, Bryckaert PE, Mandron E. Laparoscopic artificial urinary sphincter implantation in women with stress urinary incontinence: update on 13 years' experience in a single centre. BJU Int. 2019;123(5A):E14-E19. doi: 10.1111/bju.14653.

58. Zhang P, Wu ZJ, Xu L, Yang Y, Zhang N, Zhang XD. Bladder neck incision for female bladder neck obstruction: long-term outcomes. Urology. 2014;83(4):762-766. doi:10.1016/j. urology.2013.10.084

59. Olsen AL, Smith VJ, Bergstrom JO, Colling JC, Clark AL. Epidemiology of surgically managed pelvic organ prolapse and urinary incontinence. Obstet Gynecol. 1997;89(4):501-506. doi:10.1016/ S0029-7844(97)00058-6

60. Wang X, Chen Y, Hua K. Pelvic symptoms, body image, and regret after lefort colpocleisis: a long-term follow-up. J Minim Invasive Gynecol. 2017;24(3):415-419. doi:10.1016/j.jmig.2016.12.015

61. Thaweekul Y, Bunyavejchevin S, Wisawasukmongchol W, Santingamkun A. Long term results of anterior colporrhaphy with Kelly plication for the treatment of stress urinary incontinence. $J$ Med Assoc Thai. 2004;87(4):357-360.

62. Raman SV, Raker CA, Sung VW. Concomitant apical prolapse repair and incontinence procedures: trends from 2001-2009 in the United States. Am J Obstetrics Gynecol. 2014;211(3):222.e1-5. doi:10.1016/ j.ajog.2014.04.002

63. Wu YM, Reid J, Chou Q, MacMillan B, Leong Y, Welk B. Association between method of pelvic organ prolapse repair involving the vaginal apex and re-operation: a population-based, retrospective cohort study. Int Urogynecol J. 2019;30(4):537-544. doi:10.1007/s00192-018-3792-2.

64. Tolstrup CK, Lose G, Klarskov N. The Manchester procedure versus vaginal hysterectomy in the treatment of uterine prolapse: a review. Int Urogynecol J. 2017;28(1):33-40. doi:10.1007/s00192-016-3100-y

65. Oversand SH, Staff AC, Volloyhaug I, Svenningsen R. Impact of levator muscle avulsions on Manchester procedure outcomes in pelvic organ prolapse surgery. Acta Obstet Gynecol Scand. 2019. doi:10.1111/aogs.13604 
66. Kapoor S, Sivanesan K, Robertson JA, Veerasingham M, Kapoor V. Sacrospinous hysteropexy: review and meta-analysis of outcomes. Int Urogynecol J. 2017;28(9):1285-1294. doi:10.1007/s00192-0173291-x

67. Maher C, Feiner B, Baessler K, Christmann-Schmid C, Haya N, Brown J. Surgery for women with apical vaginal prolapse. Cochrane Database Syst Rev. 2016;10:Cd012376.

68. Morling JR, McAllister DA, Agur W, et al. Adverse events after first, single, mesh and non-mesh surgical procedures for stress urinary incontinence and pelvic organ prolapse in Scotland, 1997-2016: a population-based cohort study. Lancet. 2017;389(10069):629-640. doi:10.1016/S0140-6736(16)32572-7

69. Erekson E, Murchison RL, Gerjevic KA, Meljen VT, Strohbehn K. Major postoperative complications following surgical procedures for pelvic organ prolapse: a secondary database analysis of the American College of Surgeons National Surgical Quality Improvement Program. Am J Obstet Gynecol. 2017;217(5):608.e1-.e17. doi:10.1016/j.ajog.2017.05.052

70. Jelovsek JE, Barber MD, Brubaker L, et al. Effect of uterosacral ligament suspension vs sacrospinous ligament fixation with or without perioperative behavioral therapy for pelvic organ vaginal prolapse on surgical outcomes and prolapse symptoms at 5 years in the optimal randomized clinical trial. Jama. 2018;319(15):1554-1565. doi:10.1001/jama.2018.2827

71. Lukacz ES, Warren LK, Richter HE, et al. Quality of life and sexual function 2 years after vaginal surgery for prolapse. Obstet Gynecol. 2016;127(6):1071-1079. doi:10.1097/AOG.0000000000001442

72. Glazener CMA, Breeman S, Elders A, et al. Mesh, graft, or standard repair for women having primary transvaginal anterior or posterior compartment prolapse surgery: two parallel-group, multicentre, randomised, controlled trials (PROSPECT). Lancet. 2016;389 (10067):381-392. doi:10.1016/S0140-6736(16)31596-3
73. Larouche M, Geoffrion R, Walter J-E. No. 351-transvaginal mesh procedures for pelvic organ prolapse. J Obstetrics Gynaecol Canada. 2017;39(11):1085-1097. doi:10.1016/j.jogc.2017.05.006

74. Heinonen P, Aaltonen R, Joronen K, Ala-Nissila S. Long-term outcome after transvaginal mesh repair of pelvic organ prolapse. Int Urogynecol J. 2016;27(7):1069-1074. doi:10.1007/s00192-015-2939-7

75. Abbott S, Unger CA, Evans JM, et al. Evaluation and management of complications from synthetic mesh after pelvic reconstructive surgery: a multicenter study. Am J Obstetrics Gynecol. 2014;210(2):163. e1-e8. doi:10.1016/j.ajog.2013.10.012

76. Nygaard IE, McCreery R, Brubaker L, et al. Abdominal sacrocolpopexy: a comprehensive review. Obstet Gynecol. 2004;104 (4):805-823. doi:10.1097/01.AOG.0000139514.90897.07

77. Coolen AWM, van IMN, van Oudheusden AMJ, et al. Laparoscopic sacrocolpopexy versus vaginal sacrospinous fixation for vaginal vault prolapse, a randomized controlled trial: SALTO-2 trial, study protocol. BMC Womens Health. 2017;17(1):52. doi:10.1186/s12905-017-0402-2

78. Lucot JP, Cosson M, Bader G, et al. Safety of vaginal mesh surgery versus laparoscopic mesh sacropexy for cystocele repair: results of the prosthetic pelvic floor repair randomized controlled trial. Eur Urol. 2018;74(2):167-176. doi:10.1016/j.eururo.2018.01.044

79. Siddiqui NY, Grimes CL, Casiano ER, et al. Mesh sacrocolpopexy compared with native tissue vaginal repair: a systematic review and meta-analysis. Obstet Gynecol. 2015;125(1):44-55. doi:10.1097/ AOG.0000000000000570

80. Nygaard I, Brubaker L, Zyczynski HM, et al. Long-term outcomes following abdominal sacrocolpopexy for pelvic organ prolapse. Jama. 2013;309(19):2016-2024. doi:10.1001/jama.2013.4919

81. Meriwether KV, Balk EM, Antosh DD, et al. Uterine-preserving surgeries for the repair of pelvic organ prolapse: a systematic review with meta-analysis and clinical practice guidelines. Int Urogynecol J. 2019;30:505-522. doi:10.1007/s00192-019-03876-2

\section{Publish your work in this journal}

Research and Reports in Urology is an international, peer-reviewed, open access journal publishing original research, reports, editorials, reviews and commentaries on all aspects of adult and pediatric urology in the clinic and laboratory including the following topics: Pathology, pathophysiology of urological disease; Investigation and treatment of urological disease; Pharmacology of drugs used for the treatment of urological disease. The manuscript management system is completely online and includes a very quick and fair peer-review system, which is all easy to use. Visit http://www.dovepress.com testimonials.php to read real quotes from published authors. 